\title{
Knowledge, attitude and practice of pharmacists and health-care workers regarding oral contraceptives correct usage, side-effects and contraindications
}

\author{
M. Sattari, ${ }^{1}$ Z. Mokhtari, ${ }^{2}$ H. Jabari ${ }^{3}$ and S.O. Mashayekhi ${ }^{4}$
}

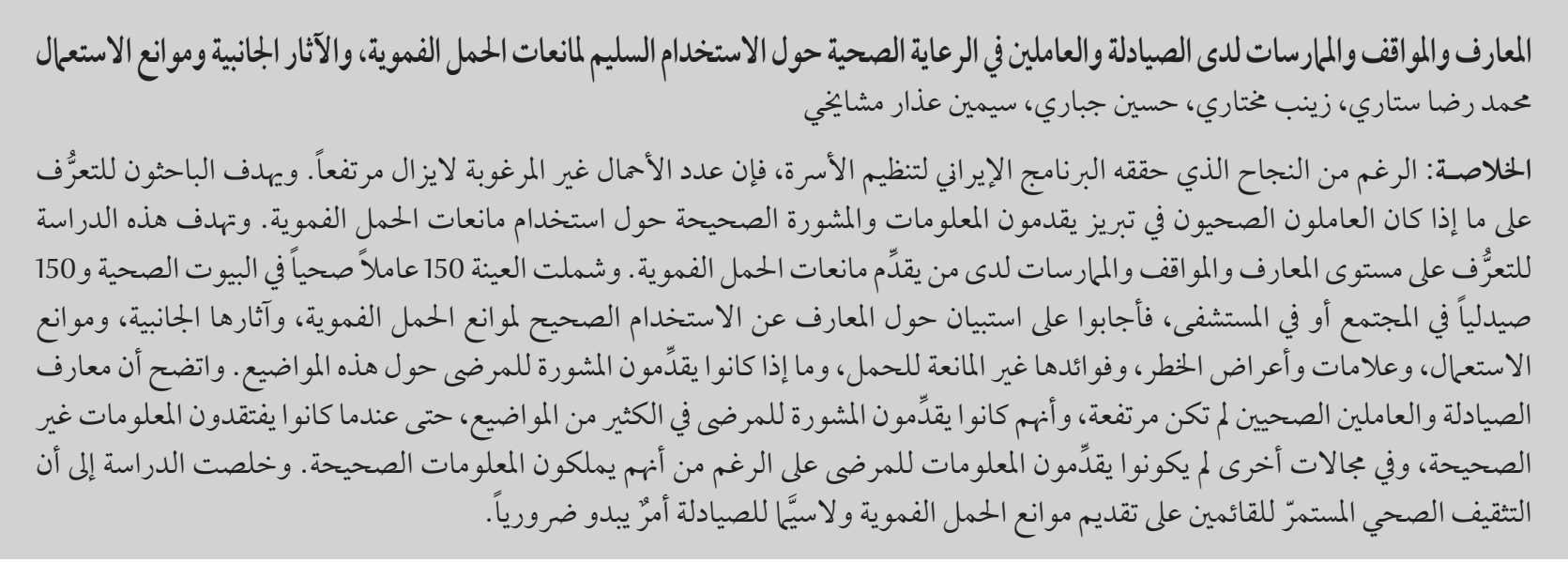

ABSTRACT Despite the success of the Iranian family planning programme, the number of unwanted pregnancies remains high. To investigate whether health workers in Tabriz are providing correct information and counselling about OCP use, the current study was planned to examine the level of knowledge, attitude and practice of OCP providers. A sample of 150 health-care workers in health houses and 150 community/hospital pharmacists answered a questionnaire about knowledge of correct use of OCP, side-effects, contraindications, danger signs/symptoms and non-contraceptive benefits, and whether they counselled patients about these subjects. Knowledge of pharmacists and health workers was not as high as expected and in many topics they were counselling patients even when they had incorrect knowledge and in other areas they were not providing information to patients despite having the correct knowledge. Better continuing education for OCP providers and especially for pharmacists seems necessary.

Connaissances, attitudes et pratiques des pharmaciens et des agents de soins de santé concernant l'utilisation correcte des contraceptifs oraux, les effets secondaires et les contre-indications

RÉSUMÉ Malgré le succès du programme de planification familiale iranien, le nombre de grossesses non désirées reste élevé. Pour savoir si les agents de soins de santé à Tabriz fournissaient des informations et des conseils adaptés sur l'utilisation des pilules contraceptives, la présente étude a été planifiée pour examiner le niveau de connaissances, les attitudes et les pratiques des personnes qui dispensent des pilules contraceptives. Un échantillon de 150 agents de soins de santé dans des maisons de santé et de 150 pharmaciens en milieu hospitalier ou communautaire ont répondu au questionnaire évaluant leurs connaissances sur l'utilisation correcte des pilules contraceptives, les effets secondaires, les contre-indications, les signes de danger/symptômes et les avantages non-contraceptifs, mais aussi sur l'offre ou non de conseils aux patientes en la matière. Les connaissances des pharmaciens et des agents de soins de santé n'étaient pas aussi bonnes qu'escomptées. De plus, sur de nombreux sujets, ils conseillaient les patientes même lorsqu'ils avaient des connaissances erronées et dans d'autres domaines, ils s'abstenaient de proposer des conseils malgré la justesse de leurs connaissances. Améliorer la formation continue des des personnes qui dispensent des pilules contraceptives, et particulièrement des pharmaciens, semble nécessaire.

${ }^{1}$ Research Centre of Infectious Disease and Tropical Medicine, Faculty of Pharmacy, Tabriz University of Medical Sciences, Tabriz, Islamic Republic of Iran ${ }^{2}$ Students' Research Committee, Tabriz University of Medical Sciences, Tabriz, Islamic Republic of Iran. ${ }^{3}$ Tabriz Health Services Management Research Center, Faculty of Medicine, Tabriz University of Medical Sciences, Tabriz, Islamic Republic of Iran. ${ }^{4}$ Tabriz Health Services Management Research Center, Faculty of Pharmacy, Tabriz University of Medical Sciences, Tabriz, Islamic Republic of Iran (Correspondence to S. Mashayekhi: mashayekhis@yahoo.co.uk). Received: 07/02/12; accepted: 06/05/12 


\section{Introduction}

From a global perspective strategies are needed for controlling the rapid worldwide population growth of recent centuries $[1,2]$, while from the individual perspective accurate and efficient methods are needed to prevent unwanted pregnancies and their adverse consequences [3]. Many factors play a role in the failure of contraception methods, including lack of knowledge about their use and side-effects. In order to provide users with useful information, health care providers need to be trained to transmit accurate and complete knowledge about contraception methods, and should be able to communicate adequately with users. According to an Iranian Ministry of Health report, the fertility rate in the Islamic Republic of Iran has decreased from 5.6 births/ woman in 1985 [4] to 1.8 births/women in 2009 [5]. This can be attributed to the Iranian family planning programme that was proposed in December 1989 and which provides free contraceptives to families via the primary health care delivery system [6]. Despite the success of this programme the number of unwanted pregnancies remains high [7], raising questions about women's compliance with contraceptive use.

Oral contraceptives pills (OCP) are one of the most effective reversible methods of preventing unwanted pregnancies. In the Islamic Republic of Iran women can obtain OCP from 2 sources: government-run health houses or community/hospital pharmacies. In the health houses health-care workers (HCW), who include midwives and family/public health educators, provide birth control methods (e.g. OCP and condoms) to families and educate them about their use. They provide a limited range of low-cost generic OCP free-ofcharge to users. OCP are also dispensed by pharmacists in community or hospital outpatient pharmacies. In addition to the cheaper OCP pharmacies also sell the more expensive brand-name OCP.
The aim of the current study was to examine the level of knowledge, attitude and practice of pharmacists and $\mathrm{HCW}$ who provide OCP to users in the Islamic Republic of Iran.

\section{Methods}

\section{Study setting and sample}

Data were collected between November 2009 and October 2010 in Tabriz, Islamic Republic of Iran. All pharmacists and HCW working in Tabriz at the time of the study were invited to enter the study. The study was conducted during obligatory continuing medical education courses for pharmacists or monthly meetings for HCW. A total of 150 pharmacists and 150 HCW participated in the study

\section{Data collection}

The aims of the study were explained to the subjects and after obtaining written consent, they completed a questionnaire. A researcher was present at the time of completion of the questionnaires to answer any questions. The subjects were free to withdraw from the study at any time. All efforts were made to protect the participant's rights and confidentiality.

The questionnaire was adopted from Gaudet et al.'s research [8] and translated into Farsi language with a few changes. The final questionnaire comprised 34 items including 6 about demographic data, and the validity and reliability of the questions were tested on 50 subjects prior to the study (Cronbach $\alpha=0.88$ ).

The questions were divided into the following sections: demographic information (age, sex, years of experience, education level); general knowledge about OCP (which OCP they provided/sold; reasons for recommending OCP; maximum duration for safe use of OCP; users' health history prior to initiation of OCP; recommended checkups for users of $\mathrm{OCP}$ ); and knowledge and counselling about OCP use (how to initiate OCP and what to do about missed pills; non-contraceptive benefits of OCP; side-effects of OCP; controversies/myths regarding OCP; and serious dangers/risks of OCP). In the knowledge and counselling section, respondents were asked to answer each knowledge topic (scored as correct, incorrect or no response) and whether they counselled patients about that topic (scored yes/no).

The different types of OCP available on the Iranian market are: high-dose generic monophasics (50 $\mu \mathrm{g}$ ethinyl estradiol/0.5 mg norgestrel), low-dose generic monophasics (30 $\mu \mathrm{g}$ ethinyl estradiol/0.3 mg norgestrel), generic triphasics, levonorgestrel (breast-feeding OCP), Marvelon (30 $\mu$ g ethinyl estradiol/150 $\mu \mathrm{g}$ desogestrel), Desoceptive (30 $\mu \mathrm{g}$ ethinyl estradiol/150 $\mu \mathrm{g}$ desogestrel), Yasmin ${ }^{\circ}$ (30 $\mu \mathrm{g}$ ethinyl estradiol/3 mg drospirenone), and cyproterone compound (35 $\mu \mathrm{g}$ ethinyl estradiol/2 mg cyproterone acetate).

\section{Analysis}

The results are reported as mean and standard deviation (SD), number and percentages. Student t-test and chisquared tests were used for analysis of quantitative and qualitative variables respectively, utilizing SPSS, version 15. A significant level of $P<0.05$ was adopted for all tests.

\section{Results}

\section{Demographic information}

The mean age of the pharmacists was 37.9 (SD 9.6) (range 23-77) years and of HCW was 37.0 (SD 4.6) (range 26-50) years with no significant difference between the 2 groups $(P=0.32)$. There was a significant sex difference between the groups; $47.3 \%$ of pharmacists and $100 \%$ of HCW were female $(P<$ $0.001)$. The average work experience of pharmacists was 13.0 (SD 8.9) (range 1-53) years while HCW had 9.3 (SD 
5.5) (1-24) years of work experience $(P$ $<0.05)$. The education level in the pharmacists' group was DPharm in all cases but was bachelor or associate degree for $65.3 \%$ and $34.7 \%$ respectively of HCW.

\section{General knowledge about OCP}

Contraceptive low-dose generic OCP were sold/provided to users by $98.7 \%$ of both groups. In the pharmacists' group the next most commonly sold formulations were high-dose generic OCP (91.3\%), levonorgestrel (80.0\%), triphasics (73.3\%), Marvelon ${ }^{\circ}$ (65.3\%), Yasmin $^{\circ}(60.7 \%)$, Desoceptive (58.7\%) and cyproterone compound (58.7\%). For the HCW group the next most common formulations provided were levonorgestrel (96.0\%), triphasics (91.3\%), high-dose generics (58.0\%) and Marvelon, ${ }^{\circ}$ Yasmin $^{\circ}$, Desoceptive ${ }^{\circ}$ and cyproterone compound (all < $10 \%)$.

The main reasons for recommendation of OCP reported by both groups was effectiveness ( $92.0 \%$ and $86.7 \%$ for HCW and pharmacists respectively). Other important reasons given by pharmacists were low price (64.0\%), ease of use (63.3\%), ease of availability (64.0\%) and reversibility (62.7\%). Other reasons given by HCW were ease of use (79.3\%), ease of availability (72.0\%), independence from husbands (61.3\%), reversibility $(58.8 \%)$ and low price (53.3\%). The average maximum duration that pharmacists recommended for safe use of OCP was 43.3 (SD 30.0) months (range 6-120 months) while this was 45.4 (SD 32.1) months (range 3-180 months) according to HCW (P $<0.05)$. Pharmacists reported that they provided OCP mainly on prescription from clinicians (50.7\%), while HCW themselves generally prescribed and provided OCP to users (76.7\%).

\section{Knowledge about initiation and use of OCP}

The most common time for tablettaking recommended by both groups was night-time before sleeping (95.2\% and $85.3 \%$ for HCW and pharmacists respectively). The opinions of pharmacists and HCW regarding the necessary questions to ask users about their health history before initiating OCP are shown in Table 1. Significantly more pharmacists recommended enquiring about users' history of diabetes, hypertension, epilepsy, coagulation diseases, past breast cancer, migraine, gallbladder disease and depression and about surgery in the near future $(P<0.001)$. Significantly more HCW recommended enquiring about history of uterus infections and liver disease $(P<0.001)$.

Around $85 \%$ of both groups knew the correct initiation method of OCP $(P>0.05)$ but only $72.7 \%$ and $47.3 \%$ of HCW and pharmacists respectively gave this information to the users ( $\mathrm{Ta}-$ ble 2).

About half of HCW and one-third of pharmacists knew what action users should take if they forgot to take 1 tablet of low- or high-dose monophasic OCPs but fewer knew what users should do about 2 or more missed pills (33.3\% and $31.9 \%$, respectively, $P>0.05)$. Despite this obvious lack of knowledge, the proportions giving counselling were fairly high ( $72.0 \%$ versus $50.7 \%$ respectively). Only $65.7 \%$ and $54.0 \%$ of HCW and pharmacists knew the correct action for 1 missed triphasic pill but much fewer knew what users should do about 2 missed triphasic pills (20.1\%

\begin{tabular}{|c|c|c|c|}
\hline \multirow[t]{2}{*}{ Health problems } & \multicolumn{2}{|c|}{$\begin{array}{l}\% \text { agreeing it is important to ask } \\
\text { about problem }\end{array}$} & \multirow[t]{2}{*}{$P$-value } \\
\hline & $\begin{array}{c}\text { HCW } \\
(n=150)\end{array}$ & $\begin{array}{l}\text { Pharmacists } \\
(n=150)\end{array}$ & \\
\hline Diabetes & 45.3 & 71.3 & $<0.001$ \\
\hline Hypertension & 76.0 & 95.3 & $<0.001$ \\
\hline Seizures or epilepsy & 45.3 & 85.3 & $<0.001$ \\
\hline Coagulation disease & 71.3 & 95.3 & $<0.001$ \\
\hline Breast cancer (past) & 64.0 & 85.3 & $<0.001$ \\
\hline Breast cancer (current) & 70.7 & 78.7 & 0.11 \\
\hline Family history of breast cancer & 54.7 & 68.0 & 0.02 \\
\hline Endocervical cancer & 36.0 & 28.0 & 0.13 \\
\hline Uterus infection & 86.0 & 65.3 & $<0.001$ \\
\hline Migraine headache & 71.3 & 96.7 & $<0.001$ \\
\hline Surgery in near future & 22.7 & 64.0 & $<0.001$ \\
\hline Gallbladder disease & 22.4 & 65.3 & $<0.001$ \\
\hline Depression & 47.3 & 71.3 & $<0.001$ \\
\hline Liver disease & 87.3 & 53.3 & $<0.001$ \\
\hline
\end{tabular}




\begin{tabular}{|c|c|c|c|c|c|c|}
\hline \multirow[t]{2}{*}{ Knowledge item } & \multicolumn{3}{|c|}{$\mathrm{HCW}(n=150)$} & \multicolumn{3}{|c|}{ Pharmacists $(n=150)$} \\
\hline & $\begin{array}{c}\% \\
\text { responding }\end{array}$ & $\begin{array}{l}\% \text { giving } \\
\text { counselling } \\
\text { on topic }\end{array}$ & $P$-value ${ }^{\mathrm{a}}$ & $\begin{array}{c}\% \\
\text { responding }\end{array}$ & $\begin{array}{l}\% \text { giving } \\
\text { counselling } \\
\text { on topic }\end{array}$ & $P$-value ${ }^{a}$ \\
\hline \multicolumn{7}{|c|}{ Instructions for initiating and use of ОСР } \\
\hline $\begin{array}{l}\text { Start OCP from } 5 \text { th day of period } \\
\text { and take } 1 \text { each day, } 1 \text { week gap, } \\
\text { start a new pack }\end{array}$ & & & $<0.001$ & & & 0.006 \\
\hline Correct & 85.4 & 72.7 & & 84.0 & 47.3 & \\
\hline Incorrect & 14.7 & 2.7 & & 12.0 & 2.7 & \\
\hline No response & 0.0 & 0.0 & & 4.0 & 0.7 & \\
\hline $\begin{array}{l}\text { If user forgets to take } \geq 1 \text { : } \\
\text { monophasic } O C P \text {, she should take }\end{array}$ & & & 0.485 & & & 0.490 \\
\hline Correct & & 71.3 & & & 49.3 & \\
\hline 1 tablet & 45.3 & & & 92.0 & & \\
\hline 2 tablets & 33.3 & & & 31.9 & & \\
\hline$>2$ tablets & 20.0 & & & 33.3 & & \\
\hline Incorrect & 1.4 & 0.7 & & 4.0 & 0.7 & \\
\hline No response & 0.0 & 0.0 & & 4.0 & 0.7 & \\
\hline $\begin{array}{l}\text { If user forgets to take } \geq 1 \text { : triphasic } \\
\text { OCP, she should take } 2 \text { tablets, } \\
\text { ifless than } 12 \mathrm{~h}\end{array}$ & & & 0.149 & & & 0.072 \\
\hline Correct & 65.3 & 48.0 & & 54.0 & 20.0 & \\
\hline Incorrect & 34.0 & 20.0 & & 40.0 & 15.3 & \\
\hline No response & 0.7 & 0.7 & & 6.0 & 0.0 & \\
\hline \multicolumn{7}{|c|}{ Non-contraceptive benefits of OCP } \\
\hline OCP should make periods lighter & & & 0.313 & & & 0.414 \\
\hline Correct & 94.7 & 60.7 & & 74.0 & 17.3 & \\
\hline Incorrect & 3.3 & 1.3 & & 24.7 & 4.0 & \\
\hline No response & 2.0 & 0.7 & & 1.4 & 0.7 & \\
\hline OCP should make periods less painful & & & 0.021 & & & 0.247 \\
\hline Correct & 93.4 & 62.7 & & 72.0 & 21.3 & \\
\hline Incorrect & 4.0 & 2.7 & & 25.3 & 4.0 & \\
\hline No response & 2.7 & 0.0 & & 2.7 & 0.7 & \\
\hline $\begin{array}{l}\text { OCP and acne: continue tablet use and } \\
\text { no need to visit doctor }\end{array}$ & & & 0.220 & & & 0.097 \\
\hline Correct & 60 & 29.3 & & 66.0 & 22.7 & \\
\hline Incorrect & 33.3 & 15.3 & & 33.3 & 7.3 & \\
\hline No response & 6.6 & 1.3 & & 0.7 & 0.7 & \\
\hline \multicolumn{7}{|c|}{ Potential problems of OCP } \\
\hline $\begin{array}{l}\text { Use of } O C P \text { with certain other } \\
\text { medications causes problems }\end{array}$ & & & 0.396 & & & 0.405 \\
\hline Correct & 88.0 & 60.0 & & 89.4 & 30.7 & \\
\hline Incorrect & 10.0 & 6.0 & & 6.0 & 3.3 & \\
\hline No response & 2.0 & 2.0 & & 4.6 & 1.3 & \\
\hline $\begin{array}{l}\text { If user does not have period after end } \\
\text { of pack: start next pack on time and } \\
\text { visit a doctor }\end{array}$ & & & 0.523 & & & 0.167 \\
\hline Correct & 50.7 & 36.0 & & 50.0 & 12.0 & \\
\hline Incorrect & 49.4 & 32.7 & & 46.0 & 6.7 & \\
\hline No response & 0.0 & 0.0 & & 4.0 & 0.0 & \\
\hline
\end{tabular}


Table 2 Pharmacists' and health-care workers' (HCW) knowledge and practice of counselling about different topics concerning oral contraceptive pill (OCP) use and side-effects (continued)

\begin{tabular}{|c|c|c|c|c|c|c|}
\hline \multirow{2}{*}{ Knowledge item } & \multicolumn{3}{|c|}{$\mathrm{HCW}(n=150)$} & \multicolumn{3}{|c|}{ Pharmacists $(n=150)$} \\
\hline & $\begin{array}{c}\% \\
\text { responding }\end{array}$ & $\begin{array}{l}\% \text { giving } \\
\text { counselling } \\
\text { on topic }\end{array}$ & $P$-value ${ }^{a}$ & $\begin{array}{c}\% \\
\text { responding }\end{array}$ & $\begin{array}{l}\% \text { giving } \\
\text { counselling } \\
\text { on topic }\end{array}$ & $P$-value ${ }^{a}$ \\
\hline
\end{tabular}

If user feels pain in thigh or calf: visit a

0.872

doctor

$\begin{array}{lrrrr}\text { Correct } & 82.0 & 54.0 & 81.4 & 16.7 \\ \text { Incorrect } & 16.6 & 11.3 & 13.4 & 2.7 \\ \text { No response } & 1.4 & 0.7 & 5.3 & 0.0\end{array}$

If user feels severe headache: take a

0.013 pain killer and visit a doctor

Correct
Incorrect
No response
If user gets break-through bleeding:
continue OCP and visit a doctor

$\begin{array}{ll}56.6 & 33.3 \\ 42.0 & 32.0\end{array}$

62.0

10.7

1.3

0.0

30.7

4.7

OCP side-effects

continue OCP and visit a doctor

0.059

0.061

$\begin{array}{lrr}\text { Correct } & 52.7 & 38.0 \\ \text { Incorrect } & 46.0 & 28.7 \\ \text { No response } & 1.3 & 0.0\end{array}$

38.0

62.0

11.3

No response

0.0

31.3

4.0

If user feels breast tenderness: continue OCP and visit a doctor

0.004

\begin{abstract}
Correct
Incorrect
\end{abstract}

No response

If user has nausea/vomiting: take OCP with food/with antiemetic/another time

Correct (at least 1 correct answer)

Incorrect

No response

$\begin{array}{rr}42.7 & 30.7 \\ 55.3 & 28.0 \\ 2.0 & 0.0\end{array}$

0.001

$\begin{array}{rr}48.0 & 10.7 \\ 42.0 & 4.0 \\ 10.0 & 0.7\end{array}$

0.019

$\begin{array}{rrrr}79.7 & 63.4 & 38.6 & 21.3 \\ 17.4 & 6.7 & 56.7 & 20.0 \\ 2.0 & 0.0 & 4.7 & 0.7\end{array}$

Controversies/ myths regarding OCP

OCP user's weight stays constant over time

0.590

0.387

$\begin{array}{lrr}\text { Correct } & 81.4 & 56.7 \\ \text { Incorrect } & 16.0 & 12.0 \\ \text { No response } & 2.6 & 1.3\end{array}$

76.7

18.0

20.6

3.3

No response

2.7

0.0

0.366 unaffected by OCP use

$\begin{array}{lrr}\text { Correct } & 82.0 & 56.7 \\ \text { Incorrect } & 14.6 & 9.3 \\ \text { No response } & 3.3 & 1.3 \\ \text { OCP use causes dry mouth } & & \\ \text { Correct } & 32.6 & 19.3 \\ \text { Incorrect } & 58.6 & 31.3 \\ \text { No response } & 8.7 & 2.0\end{array}$

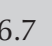

9.3

1.3

19.3

2.0
60.7

36.0

3.4

0.067

42.0

48.7

9.4

0.324
12.7

6.7

0.7

0.462

Smoking increases OCP risks

Health risks of OCP

\begin{tabular}{|c|c|c|c|}
\hline Correct & 86.0 & 54.7 & 70.0 \\
\hline Incorrect & 10.0 & 6.0 & 20.0 \\
\hline No response & 4.0 & 1.3 & 10.0 \\
\hline
\end{tabular}




\begin{tabular}{|c|c|c|c|c|c|c|}
\hline \multirow[t]{2}{*}{ Knowledge item } & \multicolumn{3}{|c|}{$\mathrm{HCW}(n=150)$} & \multicolumn{3}{|c|}{ Pharmacists $(n=150)$} \\
\hline & $\begin{array}{c}\% \\
\text { responding }\end{array}$ & $\begin{array}{l}\% \text { giving } \\
\text { counselling } \\
\text { on topic }\end{array}$ & $P$-value ${ }^{a}$ & $\begin{array}{c}\% \\
\text { responding }\end{array}$ & $\begin{array}{l}\% \text { giving } \\
\text { counselling } \\
\text { on topic }\end{array}$ & $P$-value ${ }^{\text {a }}$ \\
\hline $\begin{array}{l}\text { OCP decreases breast cancer and } \\
\text { ovarian cancer risks }\end{array}$ & & & 0.523 & & & 0.701 \\
\hline Correct & 41.3 & 26.0 & & 30.0 & 6.0 & \\
\hline Incorrect & 54.0 & 30.7 & & 58.0 & 10.0 & \\
\hline No response & 4.7 & 2.0 & & 12.0 & 1.3 & \\
\hline OCP increases endocervical cancer risk & & & $<0.001$ & & & 0.049 \\
\hline Correct & 67.3 & 43.3 & & 48.7 & 10.7 & \\
\hline Incorrect & 30.0 & 8.7 & & 40.0 & 3.3 & \\
\hline No response & 2.7 & 0.0 & & 11.4 & 0.7 & \\
\hline
\end{tabular}

${ }^{a}$ Comparing total number responding to item versus number giving counselling about item.

and 16.3\%). Despite this lack of knowledge $68.7 \%$ and $35.3 \%$ of HCW and pharmacists respectively gave advice to the users.

\section{Knowledge about non- contraceptive benefits of OCP}

Pharmacists' and HCWs' knowledge regarding the non-contraceptive benefits of OCP was determined by 3 questions (Table 2). While only $74.0 \%$ of pharmacists knew OCP could reduce bleeding during monthly periods, this was known by $94.7 \%$ of HCW $(P<0.001)$. Advising users about this information was done by HCW more than pharmacists (62.7\% versus $22.0 \%)$. About $93.4 \%$ of HCW knew that OCPs could reduce menstrual pain but only $65.4 \%$ advised users about this topic. For pharmacists knowledge about this subject was $72.0 \%$ and providing counselling was $26.0 \%$. About $60 \%$ of both groups knew that appearance of new acne was not OCPrelated or even serious and did not require a visit to a physician $(P<0.05)$. The proportions who gave advice were reasonably high (45.9\% and 30.7\% for HCW and pharmacists respectively).

\section{Knowledge about potential problems with OCP}

Almost $90 \%$ of both groups knew that drug-drug interaction with OCP could occur with some but not all medications
(Table 2). However, only 35.3\% of pharmacists provided information to users about this issue. The level of advice by HCW was twice as high $(P<0.05)$.

Only half of HCW and pharmacists knew that when there was no menstrual bleeding at the end of a pack of OCP it was necessary to start a new pack and also to visit a doctor but $36.7 \%$ and $20.1 \%$ of HCW and pharmacists respectively recommended starting a new pack and not visiting a doctor, while $12.0 \%$ and $24.3 \%$ of HCW and pharmacists recommended stopping tablets altogether.

About $80 \%$ of both groups knew that visiting a doctor was necessary when there if users had pain or oedema in the thigh or calf and $19.4 \%$ and $66.0 \%$ respectively of pharmacists and HCW said that they provided this information to users $(P<0.05)$. In case of severe headaches, $56.6 \%$ and $62.0 \%$ of $\mathrm{HCW}$ and pharmacists respectively thought that users should take pain killers and visit their doctor $(P<0.05)$ while only $37.8 \%$ and $20.1 \%$ of HCW and pharmacists knew that OCP should be discontinued. Despite this lack of knowledge, $65.3 \%$ and $16.1 \%$ of $\mathrm{HCW}$ and pharmacists said they would provide advice to users.

\section{Knowledge about OCP side- effects}

A majority of $\mathrm{HCW}$ and pharmacists (52.7\% and 62.0\% respectively) knew that breakthrough bleeding could occur during OCP use and also that users should continue tablet-taking and visit a physician if the problem persisted ( $P$ $<0.01$ ) (Table 3); $32.0 \%$ and $17.1 \%$ of HCW and pharmacists thought there was no need for a physician's visit and $14.0 \%$ of HCW and $16.2 \%$ of pharmacists believed that OCP should be stopped immediately.

Pharmacists knew that taking the tablets with food (28.0\%) or with an antiemetic $(21.0 \%)$ or at a different time of day $(30.0 \%)$ could diminish OCP induced nausea and vomiting and only $4.0 \%$ recommended discontinuation of these medications and a physician visit. HCWs knew that taking the tablets with food (39.3\%) or with an antiemetic (56.0\%) or at a different time of day (6.0\%) could diminish OCP induced nausea and vomiting and but only $10.7 \%$ said users should see a physician, while $70.1 \%$ of HCW and $42.0 \%$ of pharmacists said they provided users with this information..

Of the HCW and pharmacists $42.7 \%$ and $48.0 \%$ respectively correctly believed that breast tenderness did not need a physician visit or discontinuation 


\begin{tabular}{lccc}
\hline $\begin{array}{l}\text { Table } 3 \text { Pharmacists } \\
\text { recommendations for regular check-ups for users of oral contraceptive pills }\end{array}$ \\
\hline $\begin{array}{l}\text { \% agreeing it is necessary to } \\
\text { perform check-up }\end{array}$ & $\begin{array}{c}\boldsymbol{P} \text {-value } \\
\text { Health check-ups }\end{array}$ & $\begin{array}{c}\text { Pharmacists } \\
(\boldsymbol{n}=\mathbf{1 5 0})\end{array}$ & \\
& 88.0 & 26.0 & $<0.001$ \\
Heart and lung function & 97.3 & 68.0 & $<0.001$ \\
Hypertension & 97.3 & 86.7 & 0.001 \\
Breast examination & 92.7 & 45.3 & $<0.001$ \\
Weight & 84.7 & 47.7 & 0.03 \\
Cervical smear test & 87.3 & 47.3 & $<0.001$ \\
Varicose veins & 89.3 & 77.3 & 0.01 \\
Coagulation problems & 90.0 & 41.3 & $<0.001$ \\
Lipid profile & 58.7 & 18.7 & $<0.001$ \\
Thyroid problems & & & \\
\hline
\end{tabular}

of OCP. Although about $50 \%$ of the respondents in both groups believed users should visit a physician and about $17.0 \%$ believed they should stop taking tablets, $66.7 \%$ and $16.0 \%$ HCW and pharmacists respectively gave information about this side-effect to users $(P<$ 0.001).

\section{Knowledge about other recommendations during OCP use}

A great majority of HCW and pharmacists ( $89.6 \%$ and $70.0 \%$ respectively) knew that smoking could increase the risks associated with OCP but only $62.0 \%$ and $12.0 \%$ provided this information to users $(P<0.001)$ (Table 3$)$. While $41.3 \%$ and $30.0 \%$ of HCW and pharmacists knew that OCP could reduce ovarian and uterine cancers respectively, almost $40 \%$ of both group wrongly believed OCP could increase the risk of these cancers. Despite this lack of knowledge $58.7 \%$ of HCW said they provided users with information on these subjects. In the case of endocervical cancer, $67.3 \%$ of the respondents in HCWs group and $48.7 \%$ of pharmacists knew that OCP could increase the risk but still in HCWs and pharmacists groups, $15.1 \%$ and $30.1 \%$ thought a decreased chance of breast cancer could occur by OCP use. The rate of counselling about this issue among the $\mathrm{HCW}$ and pharmacists was $52.0 \%$ and $14.7 \%$ respectively.

The percentages of HCW and pharmacists who recommended physical examination of various organs for patients taking OCP are shown in Table 3. Significantly more HCW than pharmacists recommended regular checkups for heart and lung function, hypertension, weight, cervical smear, varicose veins, coagulation problems, lipid profile and thyroid profile.

\section{Knowledge about controversies or myths concerning $\mathrm{OCP}$}

Although $76.7 \%$ of pharmacists and $81.4 \%$ of HCW believed that OCP could increase users' body weight only about $15 \%$ of both groups believed it did not cause any weight changes and $<$ $3 \%$ of the respondents thought it could decrease weight; $70.0 \%$ and $21.3 \%$ of HCW and pharmacists gave information regarding possible changes in body weight to users (Table 2).

Whereas $82.0 \%$ and $60.7 \%$ of HCW and pharmacists believed that OCP use did not have an effect on a woman's future child-bearing $(P<0.001), 9.0 \%$ and $17.9 \%$ thought it would reduce the possibility of having children in the future; $67.3 \%$ and $20.1 \%$ of HCW and pharmacists counselled users about this subject $(P<0.001)$.
On the issue of dry mouth $32.6 \%$ and $42.0 \%$ of HCW and pharmacists believed that dry mouth caused by OCP was not an indication for drug discontinuation and could be solved by drinking extra water. Interestingly $52.6 \%$ and $15.4 \%$ of HCW and pharmacists said they had provided users with this untrue information.

\section{Discussion}

This study compared 2 groups of professionals: HCW, who were midwives and family/public health educators, and pharmacists engaged in community or hospital outpatient pharmacies. As shown in the results there were differences between these groups in the level and type of education, but there are also differences in the type and frequency of continuing education, type of clientele and responsibilities, types and prices of OCP dispensed and level of workload. HCW receive training for family planning in nursing and midwifery schools and also have monthly classes to update their information. Pharmacists are trained in schools of pharmacies and have continuing medical education after graduation, which rarely covers OCP-related topics. These could affect providers' knowledge and advice to users as seen from the results of this study.

The study highlighted 2 problems; one was the lack of or lowlevel of knowledge about OCP and the other was the low level of counselling of OCP users. When there is insufficient knowledge among providers, users will not receive information on how to use OCP, what to do when a problem occurs or which signs they should be looking out for. In the case of pharmacists, we saw a lower level of knowledge in many areas of OCP usage, side-effects, signs of problem and contraindications than for HCW. There were also areas of poor knowledge among the HCW but these were less concerning than in the pharmacists' group. In other words, $\mathrm{HCW}$ 
had a higher level of knowledge compared with pharmacists. Furthermore, HCW were more often providing counselling to users compared with the pharmacists. Nevertheless, not all knowledge resulted in counselling, which shows deficiencies in communication with OCP users. This might be as a result of lack of communication skills due to lack of training $[9,10]$, an unsuitable environment for counselling and a high number of clientele or responsibilities. Similar results were observed in previous studies in which pregnant women in Islamic Republic of Iran reported obtaining information from $\mathrm{HCW}$ rather than pharmacists [11-13].
When counselling occurs with appropriate knowledge, it is useful for users and could improve the efficacy of OCP use, but serious problems could occur when the health care providers are counselling about areas where their knowledge is poor. This means users could receive information that is incorrect and potentially dangerous. By offering further education and training for providers of OCP, and improving providers' knowledge, the value of the offered counselling will improve.

Health professionals including pharmacists need better training in communication and counselling for patients.
Improved counselling techniques, combined with a better knowledge level about OCP use, side-effects and lifethreatening problems, could improve patients' compliance with OCP use and hence reduce the problem of unwanted pregnancies.

\section{Acknowledgements}

The present study is the output of the PharmD thesis of Dr Zeynab Mokhtari (thesis No 3532, registered in Faculty of Pharmacy, Tabriz University of Medical Sciences).

Competing interests: None declared.

\section{References}

1. Nielsen R. The little green handbook: seven trends shaping the future of our planet. New York, Picador, 2006.

2. Lutz W, Sanderson W, Scherbov S. Doubling of world population unlikely. Nature, 1997, 387:803-805.

3. Moos MK, Bartholomew NE, Lohr KN. Counseling in the clinical setting to prevent unintended pregnancy: an evidencebased research agenda. Contraception, 2003, 67:115-132.

4. Vakilian K, Mirzaii K, NajmAbadi. Reproductive health in iran: international conference on population and development goals. Oman Medical Journal, 2011, 26:143-147.

5. Islamic Republic of Iran: country profile. World Health Organization, Regional Office for the Eastern Mediterranean [online database] (http://rho.emro.who.int/rhodata/?theme=countr y\&vid=10600 /, accessed 3 April 2013).

6. Aghajanian A, Mehryar AH. Fertility transition in the Islamic Republic of Iran: 1976-1996. Asia-Pacific Population Journal, 1999, 14:21-42.

7. Unwanted pregnancy rate drops in Iran. News number: 8704311063.21 July 2008. Fars News Agency [online] (http:// english.farsnews.com/newstext.php?nn=8704311063, accessed 3 April 2013).
8. Gaudet LM et al. What women believe about oral contraceptives and the effect of counseling. Contraception, 2004, 69:31-36

9. Hargie OD, Morrow NC, Woodman C. Pharmacists' evaluation of key communication skills in practice. Patient Education and Counseling, 2000, 39:61-70.

10. Greenhill $\mathrm{N}$ et al. Analysis of pharmacist-patient communication using the Calgary-Cambridge guide. Patient Education and Counseling, 2011, 83:423-431.

11. Mashayekhi SO et al. Study of awareness among pregnant women of the effects of drugs on the fetus and mother in Iran. Health Policy, 2009, 91:89-93.

12. Mashayekhi SO et al. Beliefs and practices of Iranian pregnant mothers regarding vitamins and minerals. Eastern Mediterranean Health Journal, 2011, 17:203-207.

13. Mashayekhi SO, Dilmaghanizadeh M, Ghandforoush-Sattari M. A survey on the consumption, knowledge and attitude of pregnant women toward the effects of folic acid on pregnancy outcome in Iran. Iranian Journal of Child Neurology, 2011, 5:33-40. 